\title{
Comparison of formoterol, salbutamol and salmeterol in methacholine-induced severe bronchoconstriction
}

\author{
M.J. Politiek*, M. Boorsma**, R. Aalbers*
}

Comparison of formoterol, salbutamol and salmeterol in methacholine-induced severe bronchoconstriction. M.J. Politiek, M. Boorsma, R. Aalbers. (C)ERS Journals Ltd 1999. ABSTRACT: The onset of the bronchodilating effect of formoterol (12 $\mu \mathrm{g}$ by Turbuhaler $($ ) $)$ was compared with that of salbutamol ( $50 \mu \mathrm{g}$ by Turbuhaler), salmeterol $(50 \mu \mathrm{g}$ by Diskhaler $(\mathrm{R})$ and placebo in methacholine-induced severe bronchoconstriction.

Seventeen subjects with mild-to-moderate asthma completed this randomized, double blind, cross-over, double-dummy study. On four study days, baseline forced expiratory volume in one second (FEV1) was recorded and the subjects were challenged with methacholine until FEV1 fell by at least $30 \%$. Immediately thereafter, the study drugs were inhaled and lung function was assessed for $60 \mathrm{~min}$.

The geometric mean time for FEV1 to return to $85 \%$ of baseline was 7.2 min with formoterol, $6.5 \mathrm{~min}$ with salbutamol, $14.1 \mathrm{~min}$ with salmeterol and $34.7 \mathrm{~min}$ with placebo ( $p=0.0001$, overall ANOVA). The difference between formoterol and salmeterol was statistically significant $(p=0.01)$; there was no difference between formoterol and salbutamol $(p=0.69)$.

In conclusion, formoterol reversed methacholine-induced severe bronchoconstriction as rapidly as salbutamol and more rapidly than salmeterol. Classifying $\beta_{2}$-agonists as "fast"- and "slow"- acting may be supplemental to "short"- and "long"-acting. Eur Respir J 1999; 13: 988-992.
*Dept of Pulmonology, Martini Hospital, Groningen, The Netherlands. **Astra Pharmaceutica, Zoetenneer, The Netherlands.

Correspondence: R. Aalbers, Dept of Pulmonology, Martini Hospital, Groningen, The Netherlands.

Fax: 31505245937

Keywords: Asthma

formoterol

methacholine-induced

bronchoconstriction

salbutamol

salmeterol

Received: April 161998

Accepted after revision November 111998

Supported by a research grant from Astra Pharmaceutica, the Netherlands.
In the treatment of asthma, inhaled $\beta_{2}$-agonists play an important role due to their excellent bronchodilating effect. For decades, the $\beta_{2}$-agonists salbutamol and terbutaline have proven to be life-saving in acute severe asthma and are used in the maintenance treatment on an "as needed" basis [1-3].

The newer $\beta_{2}$-agonists, salmeterol and formoterol, have a longer duration of action than the above-mentioned agonists and are, therefore, classified as long-acting $\beta_{2^{-}}$ agonists. They have been shown to be effective and welltolerated as maintenance treatment in patients with asthma, who despite optimal treatment with inhaled glucocorticosteroids have nocturnal asthma or require frequent use of inhaled short-acting $\beta_{2}$-agonists [2-7].

Salmeterol and formoterol both have a bronchodilating effect that lasts for at least $12 \mathrm{~h}$, but the onset of action of formoterol is faster than that of salmeterol and comparable to that of salbutamol [8-10]. Patients may be tempted to use their long-acting $\beta_{2}$-agonist on an "as needed" basis instead of using a separate inhaler with a short-acting bronchodilator. Thus, the present study was designed to investigate the effects of formoterol and salmeterol in acute and severe bronchoconstriction. The underlying hypothesis is that bronchodilatory effects of formoterol are as rapid as those of salbutamol, even in patients with acute asthma.

In this study, the immediate bronchodilator responses to formoterol, salbutamol, salmeterol and placebo were investigated in methacholine-induced severe bronchoconstriction.

\section{Materials and methods}

\section{Patients}

Patients with a diagnosis of asthma according to the American Thoracic Society guidelines were invited to participate in the study [1]. Inclusion criteria were the following: age 18-45 yrs; a forced expiratory volume in one second (FEV1) $>1.5 \mathrm{~L}$ and $>60 \%$ of predicted; a provocative concentration of methacholine causing a $20 \%$ fall in FEV1 $\left(\mathrm{PC}_{20}\right)<16 \mathrm{mg} \cdot \mathrm{mL}^{-1}$; no concomitant diseases or conditions that might interfere with the study; no administration of long-acting $\beta_{2}$-agonists, oral antihistamines or oral bronchodilators from $24 \mathrm{~h}$ before the enrolment visit until study completion; and no change in inhaled glucocorticosteroid dosing or use of oral steroids in the six weeks before the study.

The study was approved by the Medical Ethics Committee of the Martini Hospital, Groningen and was conducted according to Good Clinical Practice guidelines. Written informed consent was obtained from all patients.

\section{Study design}

The study was of a cross-over, randomized, doubleblind design and used a double-dummy technique for administering study drugs. The initial visit and four test days were each separated by 2-7 days. All examinations took place in the afternoon, within $2 \mathrm{~h}$ of the time of the initial 
visit. The patients withheld inhaled bronchodilators, inhaled glucocorticosteroids and cromoglycate for $6 \mathrm{~h}$ before and caffeine-containing beverages for $2 \mathrm{~h}$ before each visit.

A test day was postponed if baseline FEV 1 was $<85 \%$ or $>115 \%$ of the baseline FEV1 at enrolment. At the initial visit, the patient's inhalation technique with Turbuhaler $\mathbb{R}$ (Astra Draco, Lund, Sweden) and Diskhalerß (GlaxoWellcome, Zeist, The Netherlands) was optimalized according to the instructions of the manufacturer. A methacholine provocation test was performed in a standardized manner, however, the methacholine challenge was continued until a reduction of at least $30 \%$ in FEV1 was reached [11]. In brief, methacholine challenges were performed using a Wiesbadener Doppelinhalator giving an output of $0.2 \mathrm{~mL}$ in $2 \mathrm{~min}$. After saline, doubling concentrations of methacholine bromide from 0.125 to 64 $\mathrm{mg} \cdot \mathrm{mL}^{-1}$ dissolved in saline were inhaled at $5-\mathrm{min}$ intervals during 2 min of tidal breathing. Lung function (FEV1 and forced mid-expiratory flow between 25 and $75 \%$ of forced vital capacity (FEF25-75\%) was measured with a daily calibrated dry spirometer (Schiller SP-100; Schiller, Baar, Switzerland). Baseline values were assessed in triplicate, the highest of these FEV1 values was taken as the reference value for calculating all changes in FEV1 on that test day. Thirty and $90 \mathrm{~s}$ after completing each 2 min of tidal breathing with nebulized methacholine, single spirometry assessments were made. The lowest of these two assessments was used for the analyses. The methacholine provocation test was stopped if FEV1 fell $\geq 30 \%$ compared to baseline. The PC20 was calculated by linear interpolation of log dose versus percentage response in FEV1. All provocation tests were performed by the same technician. The study drugs were inhaled within $1 \mathrm{~min}$ of reaching a $30 \%$ fall in FEV 1 .

A single dose of study drug was inhaled from each of two blinded inhalers (Turbuhaler and Diskhaler) immediately after each other; patients with odd numbers inhaled first through Turbuhaler, those with even numbers inhaled first through Diskhaler on all test days. Turbuhaler containing formoterol (blinded Oxis $\mathbb{R}$ ) Turbuhaler, $12 \mu \mathrm{g}$ formoterol fumarate per metered-dose, mixed with lactose), salbutamol ( $50 \mu \mathrm{g}$ mixed with lactose) or placebo (lactose) and Diskhalers containing salmeterol (blinded Serevent $(\mathbb{R}$ Diskhaler, $50 \mu \mathrm{g}$ salmeterol xinafoate, mixed with lactose) or placebo (lactose) were provided by Astra Draco. Single assessments of spirometry were made at 1,3 , $5,10,15,20,25,30,40,50$ and $60 \mathrm{~min}$ after inhaling the first dose of the study drugs. After $1 \mathrm{~h}$, the bronchoconstrictor effects of methacholine were assumed to have ended. If dyspnoea became too severe during the provocation test, or within 60 min thereafter, as judged by the subject or the technician, a bronchodilator could be given and the test was to be repeated on another day. After 60 min, an inhaled bronchodilator could be given freely. A doctor was always directly available. Nebulized salbutamol was always in a standby position. Adverse events were recorded at the end of each test day.

\section{Data analysis}

The primary parameter in the statistical analysis was the time for FEV 1 to return to exactly $85 \%$ of the baseline value, i.e. when $15 \%$ fall remained. Secondary parameters included changes in FEV1 at 3 and 60 min. FEV1 values were expressed as percentage change from the baseline FEV1 on that test day. This recovery time was calculated by linear interpolation, with $0 \mathrm{~min}$ being the time of administering the first study drug dose. In cases where FEV1 did not return to $85 \%$ of baseline within $60 \mathrm{~min}$, an arbitrary time of $75 \mathrm{~min}$ was used in the analyses. For the statistical analysis of the recovery time, a base-2 log transformation was made.

A two-way fixed effects analysis of variance (ANOVA) test was used to determine treatment differences with patient, period, treatment and carry-over effect (the therapy/no therapy given in the previous test day) as factors. An additional planned analysis of covariance was performed using the highest methacholine dose given on test days as a covariate, since it was foreseen that the dose of inhaled methacholine could have a major influence on the recovery time. After breaking the code, an unplanned analysis of covariance was additionally performed using the observed percentage change in FEV1, measured just before administering the study medication, as covariate. Beforehand, the observed percentage fall in FEV1 was foreseen to be reproducible (30-40\%) and, thus, less relevant as a covariate in the analysis of the recovery time than the methacholine dose, which was anticipated to be less constant. Thus, only one covariate analysis was planned. A twosided $\mathrm{p}$-value $<0.05$ was considered significant. When treatment was statistically significant in the ANOVA or analysis of covariance (ANCOVA) model, Bonferronicorrected confidence intervals were calculated from the least-squares means, but only for the differences between formoterol and the other three study drugs; a difference between two study drugs was regarded statistically significant when $\mathrm{p}<0.017$.

In addition, the nonparametric Wilcoxon signed rank test was performed on the recovery time values after formoterol and salmeterol treatment. The data are described in the results section as means $\pm S D$, and for the log-transformed data as geometric mean values (being the anti-log of the means of log-transformed data).

The number of enrolled subjects needed was estimated to be 20 to give at least 15 fully evaluable subjects. A formal power calculation could not be performed, because of lack of knowledge on the reproducibility of the primary parameter, the recovery time.

\section{Results}

Twenty-one patients were enrolled. Two patients were withdrawn from the study because of unstable asthma (both had a baseline FEV1 on test days $<85 \%$ of the baseline FEV1 at the initial visit), one patient did not attend an agreed visit and one patient repeatedly did not show a fall in FEV 1 of at least $30 \%$ after methacholine challenge. All other patients completed the four test days without the need for an inhaled bronchodilator during the tests. Thus, 17 patients were analysed according to the per protocol approach. The four withdrawn patients were comparable to the other 17 patients in baseline lung function and $\mathrm{PC}_{20}$ methacholine. Only the data of the 17 patients who completed all four test days are shown. 
Table 1. - Characteristics of the patients who completed the study

\begin{tabular}{lc}
\hline Characteristic & Value \\
\hline Sex F/M & $12 / 5$ \\
Age yrs & $30 \pm 7(18-41)$ \\
FEV1 L & $3.29 \pm 0.79(2.09-5.17)$ \\
FEV1 \% pred & $96.4 \pm 15.6(73-122)$ \\
PC20 methacholine $\mathrm{mg} \cdot \mathrm{mL}^{-1}$ & $0.70(0.06-5.0)$ \\
Inhaled steroid use Users/nonusers & $15 / 2$ \\
$\beta_{2}$-agonist "if needed" use & $17 / 0$ \\
Users/nonusers &
\end{tabular}

Values are presented as absolute numbers or as mean $\pm \mathrm{SD}$ (range), except PC20 where median (range) is given. F: female; M: male; FEV1: forced expiratory volume in one second; $\mathrm{PC} 20$ : provocative concentration of methacholine causing a $20 \%$ fall in FEV1.

The demographic data and baseline characteristics of the patients are shown in table 1 . The patients had mild-tomoderate asthma with bronchial hyperresponsiveness.

Baseline lung function and the observed falls in FEV1 and FEF25-75\% after methacholine challenge on the four test days are shown in table 2. The results on the four test days were comparable, with the exception of a larger fall in FEV1 on the test days prior to formoterol inhalation. The overall mean fall in FEV1 was $42.5 \%$ from baseline (range 27-75\%). In four of the 68 tests, the provocation test was stopped before reaching a 30\% fall in FEV1 due to subjective dyspnoea or due to judgement of the technician; in all these cases, however, FEV1 fell by at least $25 \%$ and the data were used in the analyses. FEF $25-75 \%$ fell even more than FEV1, on average $56.7 \%$ from baseline.

In figure 1 , the geometric mean times of recovery in FEV1 after the four treatments are shown; geometric mean values for the time to recovery of FEV1 to $85 \%$ of baseline were $7.2 \mathrm{~min}$ for formoterol, $6.5 \mathrm{~min}$ for salbutamol, $14.1 \mathrm{~min}$ for salmeterol and $34.7 \mathrm{~min}$ for placebo. There was a significant treatment effect $(\mathrm{p}=0.0001$, ANOVA). As the contribution of carry-over effect was not statistically significant $(\mathrm{p}=0.48)$, it was omitted from all further analyses. In the separate comparisons, formoterol led to a significantly faster recovery than salmeterol $(p=0.01)$ and placebo $(p<0.0001)$, but not compared to salbutamol $(\mathrm{p}=0.69)$. The difference between formoterol and salmeterol was also statistically significant in the Wilcoxon signed rank test $(p=0.001)$. Recovery of FEF25$75 \%$ took more time, but showed a similar profile for the three study drugs with median values of 13.0, 13.8, 27.0

Table 2. - Lung function on the four test days before and after methacholine challenge

\begin{tabular}{lcccc}
\hline & $\begin{array}{c}\text { Baseline } \\
\text { FEV1 } \\
\% \text { pred }\end{array}$ & $\begin{array}{c}\text { Baseline } \\
\text { FEF25-75\% } \\
\mathrm{L} \cdot \mathrm{s}^{-1}\end{array}$ & $\begin{array}{c}\text { Lowest } \\
\text { FEV1 } \\
\% \text { of } \\
\text { baseline }\end{array}$ & $\begin{array}{c}\text { Lew25-75\% } \\
\% \text { of } \\
\text { baseline }\end{array}$ \\
\hline Formoterol & $95.1 \pm 15.4$ & $2.64 \pm 1.20$ & $54.6 \pm 11.7$ & $46.7 \pm 29.7$ \\
Salmeterol & $93.5 \pm 16.2$ & $2.58 \pm 1.07$ & $61.1 \pm 8.8$ & $46.4 \pm 12.8$ \\
Salbutamol & $94.9 \pm 17.5$ & $2.73 \pm 1.14$ & $59.0 \pm 8.8$ & $44.4 \pm 12.0$ \\
Placebo & $95.0 \pm 15.2$ & $2.80 \pm 1.25$ & $55.3 \pm 11.2$ & $39.8 \pm 13.2$ \\
\hline
\end{tabular}

Data are presented as mean \pm SD. FEV1: forced expiratory volume in one second; FEF25-75\%: forced mid-expiratory flow.

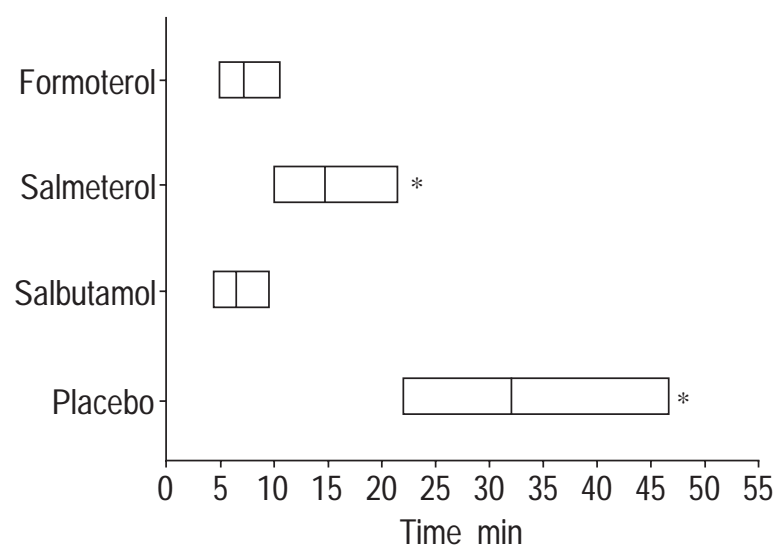

Fig. 1. - Geometric mean value and 95\% confidence interval for the time to recovery of forced expiratory volume in one second (FEV1) to $85 \%$ of baseline after a methacholine-induced fall in FEV1 of $\geq 30 \%$ with formoterol, $12 \mu \mathrm{g}$ via Turbuhaler $\mathbb{R}$; salmeterol, $50 \mu \mathrm{g}$ via Diskha-

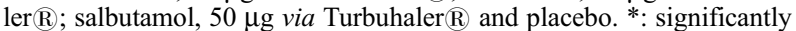
different from formoterol $(\mathrm{p}<0.017)$.

and 59.7 min after salbutamol, formoterol, salmeterol and placebo, respectively (data not shown in figure).

In the ANCOVA, where the highest inhaled methacholine concentration was used as a covariate, significance for the overall treatment effect ( $\mathrm{p}=0.0001)$ was the same as in the ANOVA without that covariate; the covariate itself was not significant $(p=0.58)$. ANCOVA, where the fall in FEV1 was used as a covariate, also yielded the same overall pvalue of 0.0001 for the treatment effect, but in this case the covariate was shown to have a statistically significant contribution ( $\mathrm{p}=0.004)$. Correcting for the fall in FEV1 (which was more pronounced before formoterol inhalation), the difference between formoterol and salmeterol became more significant $(\mathrm{p}=0.0006)$.

In six cases after placebo and in one case each after salbutamol and salmeterol inhalation, FEV1 did not recover to at least $85 \%$ of baseline within $60 \mathrm{~min}$ so an arbitrary time of 75 min was used.

The mean FEV1 after methacholine challenge and study drug inhalation are shown in figure 2 . At three and $60 \mathrm{~min}$

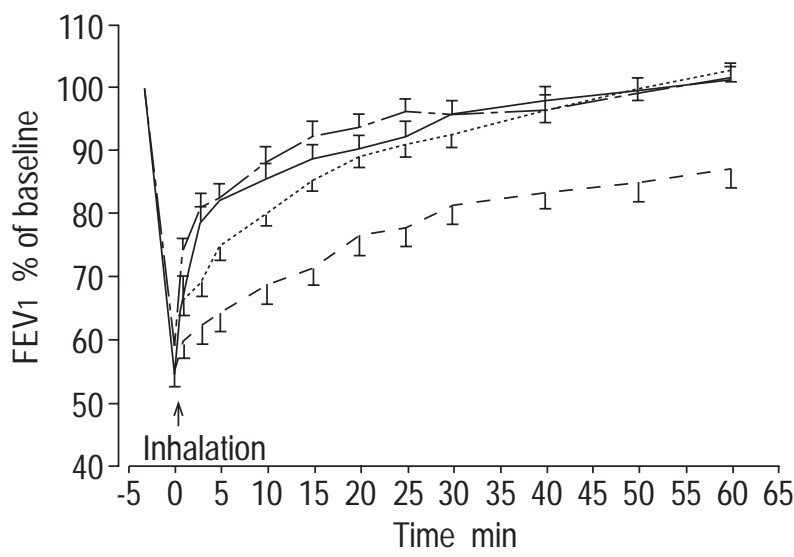

Fig. 2. - Mean \pm SEM forced expiratory volume in one second (FEV1) during the first $60 \mathrm{~min}$ following inhalation of formoterol, $12 \mu \mathrm{g}$ via

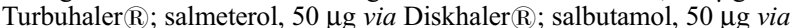
Turbuhaler $\AA$ and placebo after methacholine-induced severe bronchoconstriction. ㄴ. : formoterol; ...... : salmeterol; - - - - : salbutamol; - - - : placebo. 
after inhalation, statistical comparisons of the increases in FEV1 were undertaken. Both comparisons yielded a statistically significant treatment effect $(\mathrm{p}=0.0001$, ANOVA at $3 \mathrm{~min}$ and $\mathrm{p}=0.0004$, ANOVA at $60 \mathrm{~min})$. The increase in FEV1 3 min after inhaling formoterol $(23.9 \%$ of baseline) was significantly different from that after salmeterol $(8.0 \%, \mathrm{p}<0.0001)$ and placebo $(7.1 \%, \mathrm{p}<0.0001)$, but not different from the increase after salbutamol $(22.0 \%$, $\mathrm{p}=0.48$ ). The increase in FEV1 at $60 \mathrm{~min}$ after formoterol (46.2\% of baseline) was significantly different from the value after placebo $(31.5 \%, \mathrm{p}<0.0001)$, but not from the changes after salmeterol $(41.2 \%, \mathrm{p}=0.13)$ or salbutamol $(42.2 \%, \mathrm{p}=0.24)$. At the end of the observation period, FEV1 was on average $0.9 \%$ above baseline with formoterol, $2.3 \%$ above baseline with salmeterol, $1.2 \%$ above baseline with salbutamol and still $13.2 \%$ below baseline with placebo.

\section{Discussion}

The present study has shown a rapid onset of action of formoterol (inhaled via Turbuhaler) in severe bronchoconstriction. At the time of formoterol inhalation, mean FEV1 had fallen by $45.4 \%$ and FEF $25-75 \%$ by $53.3 \%$ compared to the baseline value. The onset of action of formoterol was as fast as salbutamol and much faster than salmeterol. One hour after administration of one of the three $\beta_{2}$-agonists at the end of the methacholine challenge, FEV1 returned to baseline. Following placebo administration, however, some bronchoconstriction remained (FEV1 was on average $13.2 \%$ below baseline). The three $\beta_{2^{-}}$ agonists had a similar effect on FEV1 $1 \mathrm{~h}$ after inhalation.

The doses of $12 \mu \mathrm{g}$ for formoterol and of $50 \mu \mathrm{g}$ for salmeterol have been shown to be equipotent in a dose response study when given as single doses to patients with stable asthma [9]. The dose of $50 \mu \mathrm{g}$ salbutamol (when inhaled via Turbuhaler), has not been compared previously to the other two test drugs, but has been shown to be equipotent with two- to four-fold higher doses of salbutamol when given via other inhalation devices [12, 13]. A dose of $200 \mu \mathrm{g}$ salbutamol via a pressurized metered-dose inhaler has been shown to induce the same maximal bronchodilating effect as both $24 \mu \mathrm{g}$ formoterol and $50 \mu \mathrm{g}$ salmeterol, also inhaled via a metered-dose inhaler [10].

The faster onset of action of formoterol compared to salmeterol has been described in previous studies concerning patients with asthma in a stable condition [8-10]. In two separate studies, the effects of salmeterol and formoterol were studied after previous inhalation of methacholine up to a $\geq 20 \%$ fall in FEV1 $[14,15]$. In one study, the recovery time with salmeterol was two-fold longer than with salbutamol [14]. In the other study, similar recovery times for formoterol and salbutamol were observed [15]. These two studies are, however, not completely comparable with the present one, as the $\beta_{2}$ agonists were administered after a $\geq 20 \%$ fall in FEV1 rather than after $\mathrm{a} \geq 30 \%$, and a different definition of recovery time was used.

It was anticipated that the dose of methacholine given would have a significant impact on the time of recovery. However, the doses given on the four test days showed little variation and, therefore, methacholine dose as a co- variate in the statistical analysis did not have a significant effect. In contrast, the day-to-day variation in the observed fall in FEV1 (with almost identical methacholine doses) was greater than expected and was found to be a statistically significant covariate. In the subsequent ANCOVA with this covariate, the difference between formoterol and salmeterol became more pronounced due to a larger observed fall in FEV1 prior to formoterol inhalation than prior to salmeterol inhalation.

In eight out of 68 provocation tests (six after placebo, one each after salmeterol and salbutamol administration), FEV1 did not recover to $85 \%$ of baseline within 60 min so an arbitrary recovery time was used in the analysis. This is considered to have had no relevant effect on the statistical analysis. In addition, a nonparametric Wilcoxon signed rank test also showed a highly significant difference in recovery time.

A possible lack of effect of one of the study drugs might have been a consequence of inadequate inhalation of the study medication or an inadequate distribution of the medication into the peripheral airways, both owing to a lack of inspiratory flow rate. The present study, however, confirms earlier clinical studies showing the effectiveness of Turbuhaler in acute asthma, including one study that specifically measured flow rates through the inhaler [16, 17].

The present model with methacholine-induced bronchoconstriction may mimic an acute episode of asthma. The extent of bronchoconstriction achieved in some patients (up to $-75 \%$ compared to baseline) was surprising and therefore it is thought that additional safeguards are needed, if this model is used in future studies. The introduction of a threshold of $1 \mathrm{~L}$ for FEV1 is thought to be useful. If FEV1 falls below $1 \mathrm{~L}$ at any moment during or after the challenge, nebulized salbutamol should be given right away.

Patients with asthma may be tempted to use their longacting bronchodilator on an "as needed" basis instead of using a separate inhaler with a short-acting bronchodilator. The results of the present study show that formoterol might be an alternative for salbutamol in acute asthma attacks, but that salmeterol is of less use. The use of formoterol as a rescue medication is in contrast to international guidelines, where "long-acting" bronchodilators are advised to be used twice daily and "short-acting" bronchodilators on an "as needed" basis [1-3]. In addition to its slower onset of action, the use of salmeterol as a rescue therapy has also been discouraged because of its supposed partial $\beta_{2^{-}}$ agonist properties, which may lead to $\beta_{2}$-blockade during overdosing $[18,19]$.

On the basis of the present study, classification of $\beta_{2-}$ agonists may need to be reconsidered: "fast"- and "slow"acting agonists could supplement that of "short"- and "long"-acting, in terms of reversing acute bronchoconstriction. A severe acute episode of asthma may lead to taking high-doses of $\beta_{2}$-agonists over a short time. A previous tolerability study showed no difference in safety between equivalent high doses of formoterol and salbutamol [20]. Clinically relevant cardiovascular and hypokalaemic side-effects were not observed during administration of high-doses of formoterol (up to $228 \mu \mathrm{g}$ ) and salbutamol (up to $3,800 \mu \mathrm{g}$ ) [20]. However, additional safety studies with long-term treatment of formoterol "as needed" are required, before considering changing asthma management strategies. 
The results of this study show that formoterol via Turbuhaler is as fast as salbutamol via Turbuhaler and faster than salmeterol via Diskhaler in reversing methacholineinduced severe bronchoconstriction.

\begin{abstract}
Acknowledgements. The authors thank T.H. Winter for performing the methacholine challenges, Astra Draco for preparing blinded medication and G.D. Nossent, W.J. Snoek, C.G. Tol and S.H. Wills for their contribution to the study.
\end{abstract}

\section{References}

1. American Thoracic Society. Standards for the diagnosis and care of patients with COPD and asthma. Am Rev Respir Dis 1987; 136: 225-244.

2. Global Initiative for Asthma. Global strategy for asthma management and prevention. Washington, D.C., National Heart, Lung, and Blood Institute, 1995 (Publication no. 95-3659).

3. The British Guidelines on Asthma Management. 1995 Review and position statement. Thorax 1997; 52 (Suppl. 1): $\mathrm{S} 1-\mathrm{S} 21$.

4. Schreurs AJM, Sinninghe Damsté HEJ, de Graaff CS, Greefhorst APM. A dose-response study with formoterol Turbuhaler as maintenance therapy in asthmatic patients. Eur Respir J 1996; 9: 1678-1683.

5. Van der Molen T, Postma DS, Turner MO, et al. Effects of the long-acting $\beta$-agonist forrnoterol on asthma control in asthmatic patients using inhaled corticosteroids. Thorax 1997; 52: 535-539.

6. Fuller R. Safety of salmeterol in the treatment of asthma. Eur Respir Rev 1995; 5: 133-137.

7. Pauwels RA, Löfdahl C-G, Postma DS, et al. Effect of inhaled formoterol and budesonide on exacerbations of asthma. N Engl J Med 1997; 337: 1405-1411.

8. Wegener T, Hedenström H, Melander B. Rapid onset of action of inhaled formoterol in asthmatic patients. Chest 1992; 102: 535-538.

9. Palmqvist M, Persson G, Lazer L, Rosenborg J, Larsson P, Lötvall J. Inhaled dry-powder formoterol and salmeterol in asthmatic patients: onset of action, duration of effect and potency. Eur Respir J 1997; 10: 2484-2489.
10. Van Noord JA, Smeets JJ, Raaijmakers JAM, Bommer AM, Maesen FPV. Salmeterol versus formoterol in patients with moderately severe asthma: onset and duration of action. Eur Respir J 1996; 9: 1684-1688.

11. Sterk PJ, Fabbri LM, Quanjer PhH, et al. Airway responsiveness. Standardized challenge testing with pharmacological, physical and sensitizing stimuli in adults. Eur Respir J 1993; 6: Suppl. 16, 53-83.

12. Mahadewsingh JV, Hamersma WBGJ, Schreurs AJM. Relative efficacy of three different inhalers containing salbutamol in patients with asthma. Eur J Clin Pharmacol 1996; 50: 467-469.

13. Löfdahl CG, Andersson L, Bondesson E, et al. Differences in bronchodilating potency of salbutamol in Turbuhaler as compared with a pressurized metered-dose inhaler formulation in patients with reversible airway obstruction. Eur Respir J 1997; 10: 2474-2478.

14. Beach JR, Young CL, Stenton SC, Avery AJ, Walters EH, Hendrick DJ. A comparison of the speeds of action of salmeterol and salbutamol in reversing methacholineinduced bronchoconstriction. Pulm Pharmacol 1992; 5: 133-135.

15. Beach JR, Bromly CL, Avery AJ, Reid RWEC, Walters $\mathrm{EH}$, Hendrick DJ. Speeds of action of single doses of formoterol and salbutamol compared with placebo in reversing methacholine-induced bronchoconstriction. Pulm Pharmacol 1996; 9: 245-249.

16. Tonnesen F, Laursen LC, Evald T, Stahl E, Ibsen TB. Bronchodilator effect of terbutaline powder in acute severe bronchial obstruction. Chest 1994; 105: 697-700.

17. Brown PH, Ning ACWS, Greening AP, McLean A, Crompton GK. Peak inspiratory flow through Turbuhaler in acute asthma. Eur Respir J 1995; 8: 1940-1941.

18. Smyth ET, Pavord ID, Wong CS, Wisniewski AFZ, Williams J, Tattersfield AK. Interaction and dose equivalence of salbutamol and salmeterol in patients with asthma. Br Med J 1993; 306: 543-545.

19. Källström BL, Sjöberg J, Waldeck B. The interaction between salmeterol and $\beta_{2}$-adrenoceptor agonists with higher efficacy on guinea pig trachea and human bronchus in vivo. Br J Pharmacol 1994; 113: 687-692.

20. Maesen FPV, Costongs RJMG, Smeets JJ, Brombacher PJ, Zweers PGMA. The effect of maximal doses of formoterol and salbutarnol from a metered-dose inhaler on pulse rates, ECG, and serum potassium concentrations. Chest 1991; 99: 1367-1373. 